Article

\title{
Flexible Carbon Electrodes for Electrochemical Detection of Bisphenol-A, Hydroquinone and Catechol in Water Samples
}

\author{
Acelino C. de Sá ${ }^{1,2}$, Simone C. Barbosa ${ }^{1,2}$, Paulo A. Raymundo-Pereira ${ }^{1}$, Deivy Wilson ${ }^{1}$, \\ Flávio M. Shimizu ${ }^{3}\left(\mathbb{D}\right.$, Maria Raposo ${ }^{2, *(\mathbb{D})}$ and Osvaldo N. Oliveira Jr. ${ }^{1, *}$ \\ 1 São Carlos Institute of Physics, University of São Paulo-USP, São Carlos, 13566-590 São Paulo CEP, Brazil; \\ acelino@usp.br (A.C.d.S.); simonebarbosa@ifsc.usp.br (S.C.B.); pauloraymundo@ifsc.usp.br (P.A.R.-P.); \\ dwilson@ifsc.usp.br (D.W.) \\ 2 CEFITEC, Physics Department, Faculty of Science and Technology, Universidade Nova de Lisboa, \\ Campus de Caparica, 2829-516 Caparica, Portugal \\ 3 Department of Applied Physics, “Gleb Wataghin” Institute of Physics (IFGW), University of \\ Campinas (UNICAMP), 13083-859 Campinas, São Paulo, Brazil; fshimizu@unicamp.br \\ * Correspondence: mfr@fct.unl.pt (M.R.); chu@ifsc.usp.br (O.N.O.J.); Tel.: +351-21-294-8576 (M.R.); \\ +55-16-3373-9825 (O.N.O.J.)
}

Received: 15 September 2020; Accepted: 14 October 2020; Published: 17 October 2020

\begin{abstract}
The detection of pollutant traces in the public water supply and aquifers is essential for the safety of the population. In this article, we demonstrate that a simple electrochemical procedure in acidic solution can be employed for enhancing the sensitivity of flexible screen-printed carbon electrodes (SPEs) to detect bisphenol-A (BPA), hydroquinone, and catechol, simultaneously. The SPEs were pretreated electrochemically in $\mathrm{H}_{2} \mathrm{SO}_{4}$ solution, which did not affect their morphology, yielding high current signals with well separated oxidation peaks. The sensitivity values were $0.28,0.230$, and $0.056 \mu \mathrm{A} \mathrm{L} \mu \mathrm{mol}^{-1}$ with detection limits of $0.12,0.82$, and $0.95 \mu \mathrm{mol} \mathrm{L}^{-1}$ for hydroquinone, catechol, and BPA, respectively. The sensors were reproducible and selective for detecting BPA in plastic cups, and with adequate specificity not to be affected by interferents from water samples. The simple, inexpensive, and flexible SPE may thus be used to detect emerging pollutants and monitor the water quality.
\end{abstract}

Keywords: flexible carbon electrodes; electrochemical sensor; emerging pollutants; bisphenol-A; hydroquinone and catechol; water samples

\section{Introduction}

The detection of pollutant traces is crucial for guaranteeing the safety of public water supply and aquifers, which can be contaminated by pesticides [1], industrial products, personal hygiene pharmaceutical products (PPCPs) [2-5], and other emerging contaminants [6]. Among the latter contaminants, attention has been paid to plastic packaging containing bisphenol A (2,2-bis (4-hydroxyphenyl) propane) (BPA), a poorly water-soluble compound $\left(5.2 \times 10^{-4} \mathrm{~mol} \mathrm{~L}^{-1}\right)$ used in manufacturing [7] of polycarbonate plastics and epoxy resins $[4,8,9]$. Byproducts of BPA from these plastics may be released into the environment and groundwater [8], contaminate food, and affect people using healthcare equipment, contact lenses, dental composites, toys, storage media, windows foils, and spectacle lenses [8,10,11]. Of special relevance is water ingestion using plastic cups since BPA may migrate from plastic to water particularly at hot water temperatures [9]. BPA may react with residual chlorine and release a toxic chlorinated byproduct that can alter endocrine functions [11-14]. The concern about possible serious effects from BPA on the environment and humans has motivated the use of various detection methods, including enzyme-linked immune sorbent 
assays (ELISA), liquid chromatography-mass spectrometry (LC-MS), surface-enhanced Raman scattering (SERS), high-performance liquid chromatography (HPLC), and gas chromatography-mass spectrometry (GC-MS). The application of these methods requires sample pretreatment, which is time-consuming $[13,15]$ and elevates operating costs. Furthermore, the operation must be performed by specialized personnel and these methods are unsuitable for point-of-care detection [16].

An alternative to these high-cost methods is to employ electrochemical sensors whose sensitivity, portability, fast response, and low cost $[15,17]$ have been exploited in monitoring the environment [18] and food processing $[19,20]$, in addition to medical diagnosis [21]. These sensors can be made with a variety of materials, including quantum dots, composites containing metal nanoparticles, carbon-based materials and aptamers [15]. Molecularly imprinted polymers (MIP) can also be used in electrochemical sensing owing to their recognition sites at the nanoscale, high surface area, and selectivity towards target molecules [22,23]. With regard to BPA, perhaps the most important challenge is to reach a sufficient sensitivity and selectivity for detection in real samples that contain a mixture of various contaminants [24]. The main difficulty arises from the high oxidation potential of BPA, which justifies the search for materials providing a large number of active sites for BPA oxidation [15]. In this work, we demonstrate that a simple electrochemical procedure in acidic solution can be used to enhance the sensitivity of flexible screen-printed electrodes (SPEs) made with carbon-based materials which may be applied even to non-planar surfaces. It is shown that the SPEs can not only detect BPA, but also hydroquinone and catechol, including in water samples from aquifer ducts or pipelines.

\section{Materials and Methods}

Bisphenol-A (BPA), pyrocatechol, epinephrine, hydroquinone, paracetamol, and acetonitrile were purchased from Sigma-Aldrich, while carbon conductive ink (BQ221) was acquired from Dupont (USA). All solutions were prepared with ultrapure water (Millipore Milli-Q) with a resistivity of 18 $\mathrm{M} \Omega \mathrm{cm}$. Phosphate buffer solutions $\left(0.1 \mathrm{~mol} \mathrm{~L}^{-1}\right)$ were prepared using $\mathrm{NaH}_{2} \mathrm{PO}_{4}$ and $\mathrm{Na}_{2} \mathrm{HPO}_{4}$ acquired from Sigma-Aldrich. The screen-printed carbon electrodes (SPEs) were designed in AutoCAD software (Autodesk, Mill Valley, CA, USA) and transferred to 150-thread polyester screens covered with photosensitive resin using the protocol of ref. [25]. As depicted in Scheme 1, the electrodes were made by printing a layer of carbon conductive ink BQ221 on the flexible polyethylene terephthalate (PET) substrate and dried in an oven at $90^{\circ} \mathrm{C}$ for $15 \mathrm{~min}$. The working area of the flexible devices was delimited with double-sided tape. Scanning electron microscopy (SEM) images and X-ray dispersive energy spectra (EDS) were acquired with a ZEISS, model SIGMA microscope, equipped with field emission electron gain (SEM-FEG) and OXFORD system.

Electrochemical experiments were performed in an Autolab PGSTAT 204 potentiostat/galvanostat controlled with Nova 2.0 software (Autolab), using SPEs with the three electrodes embedded, viz. the working, reference, and auxiliary electrodes. Differential pulse voltammetry (DPV) was performed in a potential range between -0.6 and $+1.0 \mathrm{~V}$ at a scan rate of $5 \mathrm{mV} \mathrm{s}^{-1}$, with a pulse amplitude of $50 \mathrm{mV}$ and modulation time of $1 \mathrm{~ms}$. Analytical curves for individual and simultaneous detection of hydroquinone, catechol, and BPA were made with SPEs submitted to a simple pre-treatment step using chronoamperometry at $+2.5 \mathrm{~V}$ for $120 \mathrm{~s}$ in $0.1 \mathrm{~mol} \mathrm{~L}^{-1}$ sulfuric acid solution [26]. After electrochemical pre-treatment, the flexible electrodes were washed with ultrapure water to remove the acidic solution from the electrode followed by immersion in $0.1 \mathrm{~mol} \mathrm{~L}^{-1}$ phosphate buffer solution for the measurements in blank solutions. Each analytical curve was performed using one flexible SPE. All measurements were carried out in triplicate and the relative standard deviation (RSD) was calculated for each concentration. The standard deviation of $y$ (peak current)-intercept $(S y)$ in the linear regression, used to fit peak current versus concentration plots, was considered to estimate the limit of detection (LOD) and quantification (LOQ) or limit of determination. The definitions employed were LOD $=3.0 \mathrm{Sy} / \mathrm{b}$, and LOQ $=10 \mathrm{Sy} / \mathrm{b}$, where $S y$ is the standard deviation of the $y$ (peak current)-intercept and $b$ is the slope of the regression line [27]. For sample preparation, $4.799 \mathrm{~g}$ of plastic cups were cut into small pieces and heated at 
$100{ }^{\circ} \mathrm{C}$ for $20 \mathrm{~min}$ in a beaker containing $200 \mathrm{~mL}$ of water. The water sample was analyzed using standard additions.

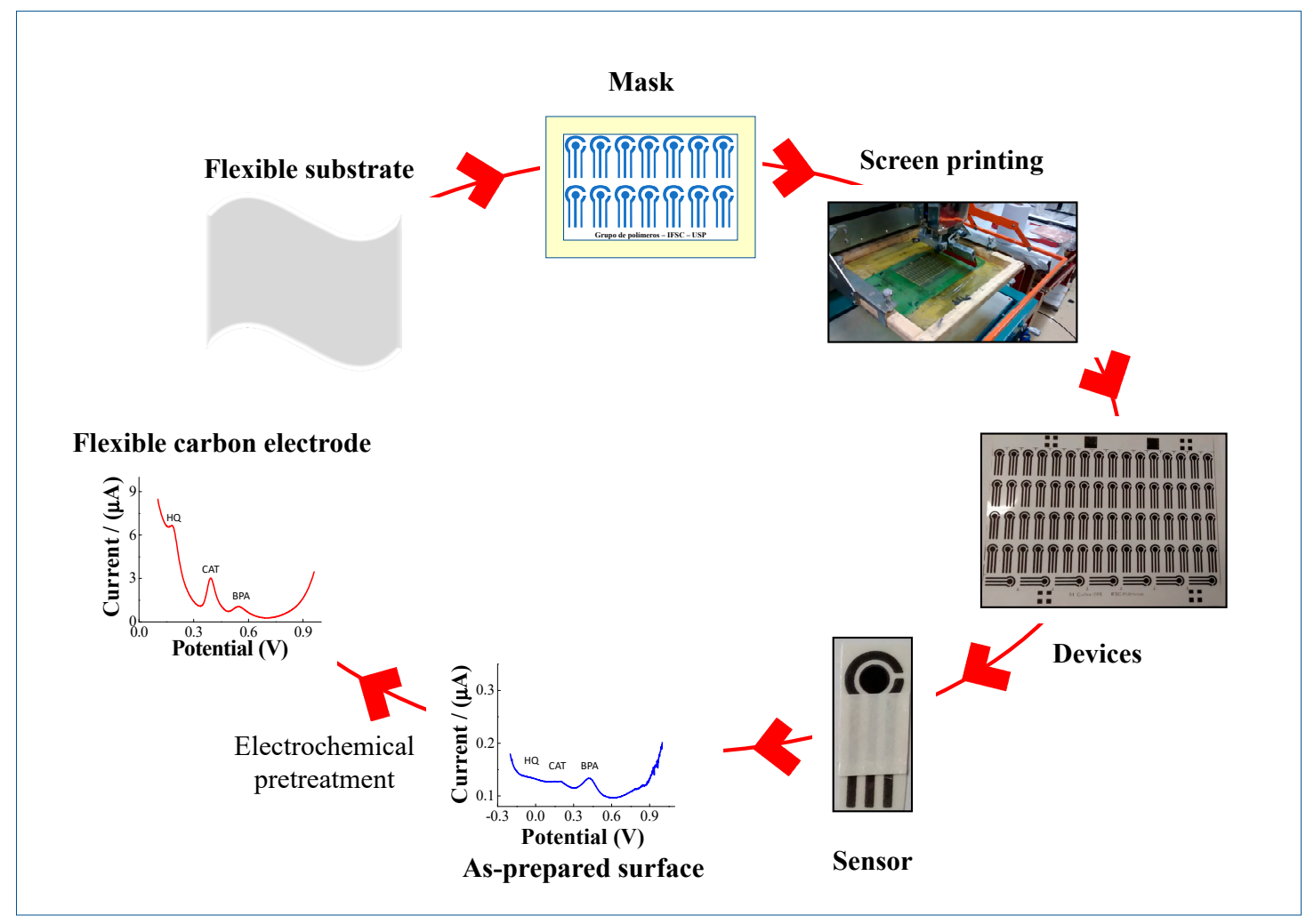

Scheme 1. Schematic representation of device preparation using screen printing technology and electrochemical sensors. Also indicated is electrochemical sensing with as-prepared sensors and with sensors submitted to an electrochemical treatment in acidic solution.

\section{Results}

Figure 1A shows DP voltammograms with small current signals and ill-defined anodic peaks for simultaneous detection of hydroquinone, catechol, and BPA using the flexible SPEs without previous pretreatment. The anodic peak current increased linearly from $5 \times 10^{-6}$ to $30 \times 10^{-6} \mathrm{~mol} \mathrm{~L}^{-1}$ for the three analytes as shown in Figure 1B. The equations from the linear regression in calibration plots are $\mathrm{I}(\mu \mathrm{A})=(9.9 \pm 1.8) \times 10^{-9}+(0.023 \pm 0.001) C_{\text {hydroquinone }}\left(\mu \mathrm{mol} \mathrm{L}^{-1}\right) ; \mathrm{I}(\mu \mathrm{A})=(2.1 \pm 2) \times 10^{-8}+(0.027 \pm 0.001)$ $\mathrm{C}_{\text {catechol }}\left(\mu \mathrm{mol} \mathrm{L}{ }^{-1}\right)$ and I $(\mu \mathrm{A})=(5.2 \pm 1.2) \times 10^{-7}+(0.124 \pm 0.007) \mathrm{C}_{\mathrm{BPA}},(\mu \mathrm{mol} \mathrm{L}-1)$, with detection limits of $2.4 \times 10^{-6}, 2.4 \times 10^{-6}$ and $2.9 \times 10^{-6} \mathrm{~mol} \mathrm{~L}^{-1}$ for hydroquinone, catechol, and BPA, respectively. After applying the electrochemical pretreatment, higher anodic peak currents and well-defined peaks were observed for hydroquinone, catechol, and BPA in Figure 1C, in comparison with the results in Figure 1A. The oxidation peaks at $0.02,0.11$, and $0.45 \mathrm{~V}$ increased linearly from $9.9 \times 10^{-7}$ to $50.0 \times 10^{-6}$ $\mathrm{mol} \mathrm{L}^{-1}$, as shown in Figure 1D. The linear regression for calibration plots were $\mathrm{I}(\mu \mathrm{A})=(2.1 \pm 0.1) \times 10^{-7}$ $+(0.28 \pm 0.01) C_{\text {hydroquinone }}\left(\mu \mathrm{mol} \mathrm{L}^{-1}\right) ; \mathrm{I}(\mu \mathrm{A})=(3.7 \pm 0.6) \times 10^{-7}+(0.230 \pm 0.008) C_{\text {catechol }}\left(\mu \mathrm{mol} \mathrm{L}^{-1}\right)$ and $\mathrm{I}(\mu \mathrm{A})=(0.7 \pm 1.8) \times 10^{-8}+(0.056 \pm 0.002) C_{\mathrm{BPA}}\left(\mu \mathrm{mol} \mathrm{L}^{-1}\right)$. The electrooxidation mechanism of hydroquinone, catechol, and BPA involves transfer of two electrons and two protons [18,28,29]. The peaks at $0.02,0.11$, and $0.45 \mathrm{~V}$ were attributed to the well-established route for oxidation of hydroquinones, phenols and derivatives of the quinine form [19,29]. The detection limit was $1.2 \times 10^{-7}, 8.2 \times 10^{-7}$, and $9.5 \times 10^{-7} \mathrm{~mol} \mathrm{~L}^{-1}$ for hydroquinone, catechol, and BPA, respectively. The slopes of calibrations plots changed after detection of $50 \mu \mathrm{mol} \mathrm{L}{ }^{-1}$ due to the adsorption of molecules at the electrode surface. This should not be considered a limitation because the flexible carbon electrodes are disposable with a low cost of production, and can be used in only one detection procedure. These results confirm the 
efficiency of the electrochemical pretreatment with a four-fold increase in sensitivity compared to the unmodified SPE. The enhanced sensitivity is attributed to the removal of non-electroactive components such as resins, solvents, and additives from the carbon ink induced by the pretreatment. This increases the electroactive area at the working electrode surface, which leads to a nanostructured film on the electrode-solution interface comprising graphite and carbon nanoparticles (Carbon Black) [30].
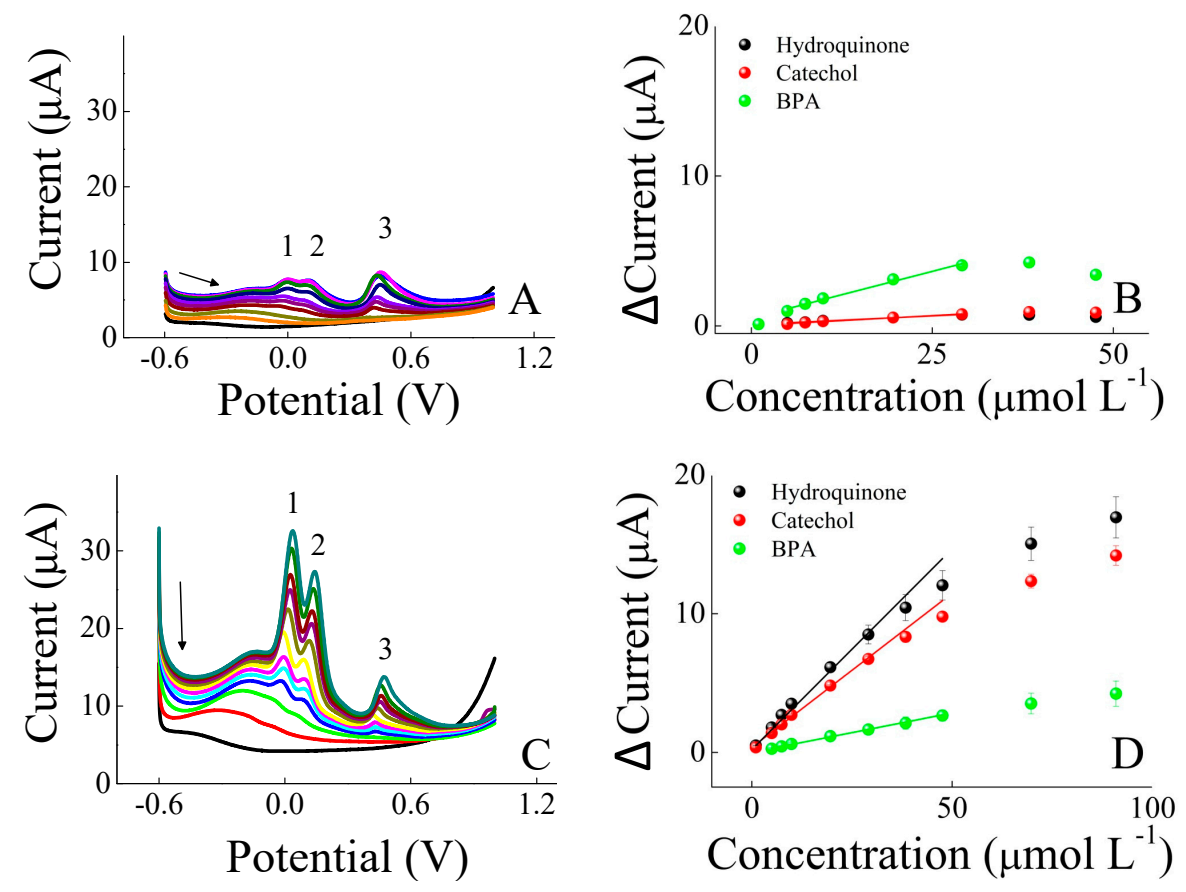

Figure 1. (A) Differential Pulse Voltammetry (DPV) data for simultaneous detection of (1) hydroquinone, (2) catechol, and (3) BPA using flexible SPEs before electrochemical pretreatment, (B) Calibration curves for SPEs before electrochemical pretreatment, (C) Differential Pulse Voltammetry (DPV) data for simultaneous detection of (1) hydroquinone, (2) catechol and (3) BPA using SPEs after electrochemical pretreatment and (D) Calibration curves for SPEs after electrochemical pretreatment. Conditions: concentration range from 0.5 to $90 \times 10^{-6} \mathrm{~mol} \mathrm{~L}^{-1}$, in phosphate buffer solution $0.1 \mathrm{~mol} \mathrm{~L}^{-1}, \mathrm{pH}$ 7.0.

SEM images of flexible SPEs were collected to assess if the morphology of SPEs is unaffected by the electrochemical pretreatment. As shown in Figure 2A,B, similar surfaces are observed for the electrode before and after the activation process. The EDX spectra in Figure 3 point to a higher carbon count and a slight decrease in oxygen for the SPE after electrochemical pretreatment. This suggests that the treatment does not introduce functional groups on the electrode surface but removes non-electroactive materials such as polymers and chemicals from the carbon ink used in printing the SPEs. Well-defined peaks from the redox probe $\left[\mathrm{Fe}(\mathrm{CN})_{6}\right]^{4-/ 3-}$ were observed with SPEs before and after electrochemical pretreatments (see Supplementary Figure S1 and Table S1). The $\triangle \mathrm{Ep}$ (Epa-Epc) value of $0.56 \mathrm{~V}$ vs. C. indicates faster electrochemical kinetics after pretreatment in $0.1 \mathrm{~mol} \mathrm{~L}^{-1}$ of $\mathrm{H}_{2} \mathrm{SO}_{4}$ solution using chronoamperometry at an applied potential of $-2.5 \mathrm{~V}$ vs. $\mathrm{C}$ for $120 \mathrm{~s}$ [31]. The amount of electroactive species $\left(\Gamma / \mathrm{mol} \mathrm{cm}^{-2}\right)$ was estimated using $\Gamma=\mathrm{Q} / \mathrm{nFA}$ [18], where $Q(\mathrm{C})$ is the background-corrected electric charge, estimated by integrating the anodic peaks of Figure $S 1 ; n$ is the number of electrons; $F$ is the Faraday constant (96 $\left.485.34 \mathrm{C} \mathrm{mol}^{-1}\right)$; and $A$ is the surface geometric area $\left(0.071 \mathrm{~cm}^{2}\right) . Q$ was $1.23 \times 10^{-4}$ and $9.36 \times 10^{-4}$ $C$, and the estimated surface concentration was $1.23 \times 10^{-7}$ and $0.61 \times 10^{-7} \mathrm{~mol} \mathrm{~cm}^{-2}$ at the flexible SPEs before and after the electrochemical pretreatment, respectively. The pretreatment produces an increase in the number of electroactive carbons on the surface, thus increasing the sensitivity toward hydroquinone, catechol and bisphenol A as depicted in Figure 1D. The pretreated flexible SPE could be stored under ambient conditions for 30 days with an average decrease of $10 \%$ in the initial current 
value $[20,31]$. All subsequent experiments were performed with SPEs electrochemically pretreated with a sulfuric acid solution and using chronoamperometry.
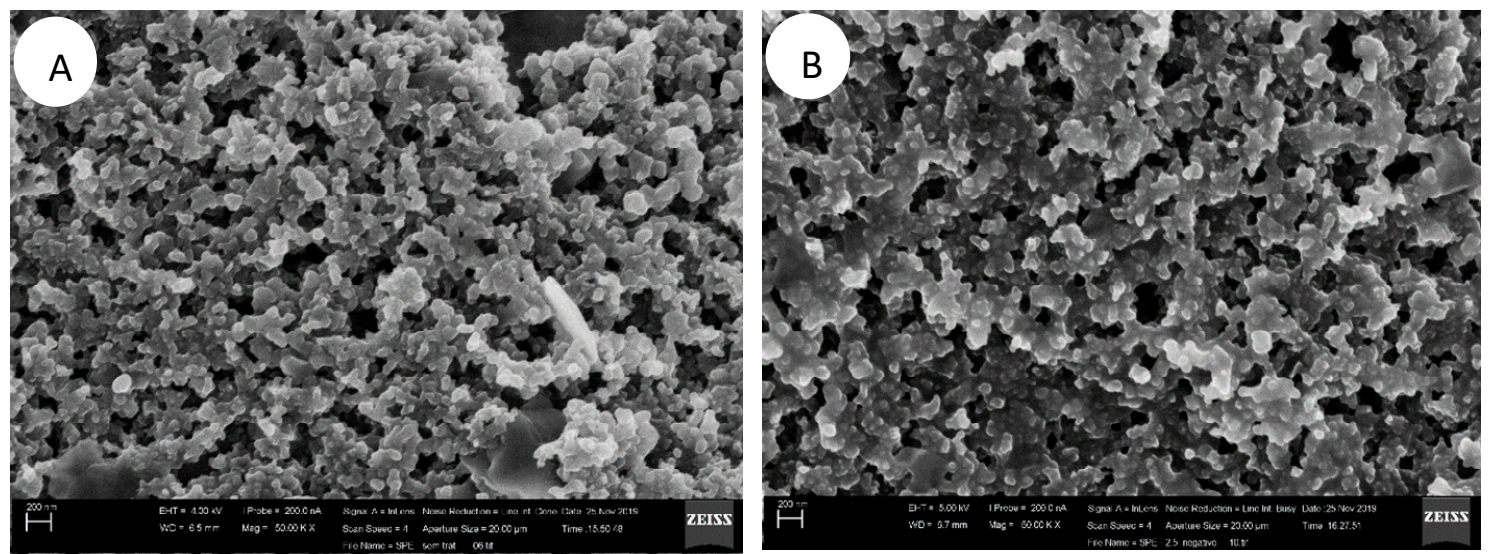

Figure 2. SEM-FEG images of flexible SPES before (A) and after (B) electrochemical pretreatment.
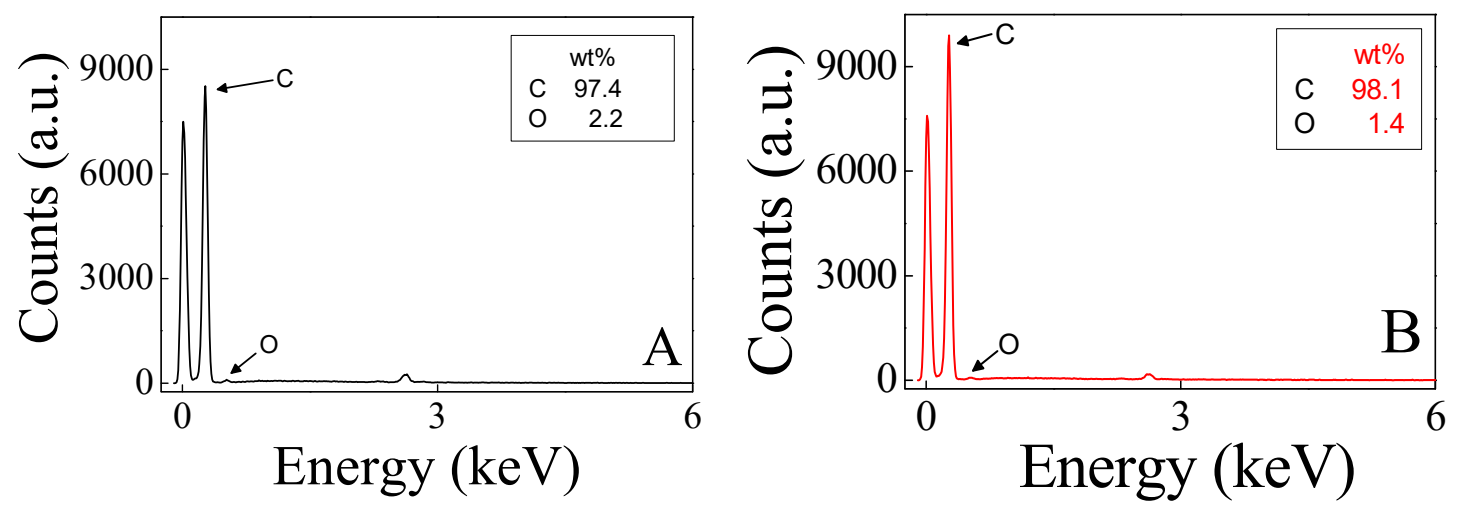

Figure 3. EDS spectra for flexible SPEs before (A) and after (B) electrochemical pretreatment.

Figure 4 shows DP voltammograms with flexible SPEs for the individual detection of hydroquinone, catechol, and BPA from oxidation peaks at $0.02 \mathrm{~V}, 0.03 \mathrm{~V}$, and $0.25 \mathrm{~V}$ vs. C, respectively. A comparison in Figure 5 indicates that the slopes of the analytical curves are similar for individual and simultaneous detection: for hydroquinone, the slopes were $0.25 \pm 0.01$ and $0.28 \pm 0.01$; for catechol $0.28 \pm 0.02$ and $0.22 \pm 0.01$; and for BPA $0.05 \pm 0.02$ and $0.06 \pm 0.01$. The oxidation peaks for individual and simultaneous BPA detection were centered at 0.25 and 0.45 ( $\mathrm{V}$ vs $\mathrm{C}$.), respectively. The change in the anodic peak potential can be attributed to the adsorption of other components on the flexible SPE leading to a potential shift. However, this will not be a problem for detection because the slopes did not vary significantly $(0.046 \pm 0.02$ and $0.056 \pm 0.01$ for individual and simultaneous detection, respectively). It is, therefore, possible to apply flexible SPEs for BPA detection in water analysis containing hydroquinone and catechol. 

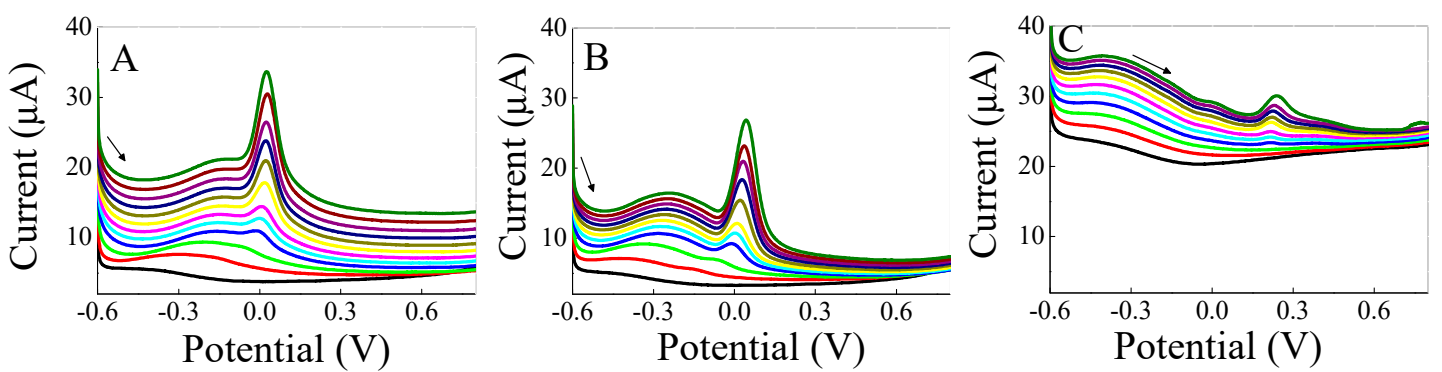

Figure 4. Differential Pulse Voltammograms data for individual electrooxidation of hydroquinone in (A), catechol in (B), and BPA in (C), using flexible SPEs after electrochemical pre-treatment. Conditions: concentration range from 0.5 to $90 \times 10^{-6} \mathrm{~mol} \mathrm{~L}^{-1}$ in phosphate buffer solution $0.1 \mathrm{~mol} \mathrm{~L}^{-1}$, $\mathrm{pH}$ 7.0.

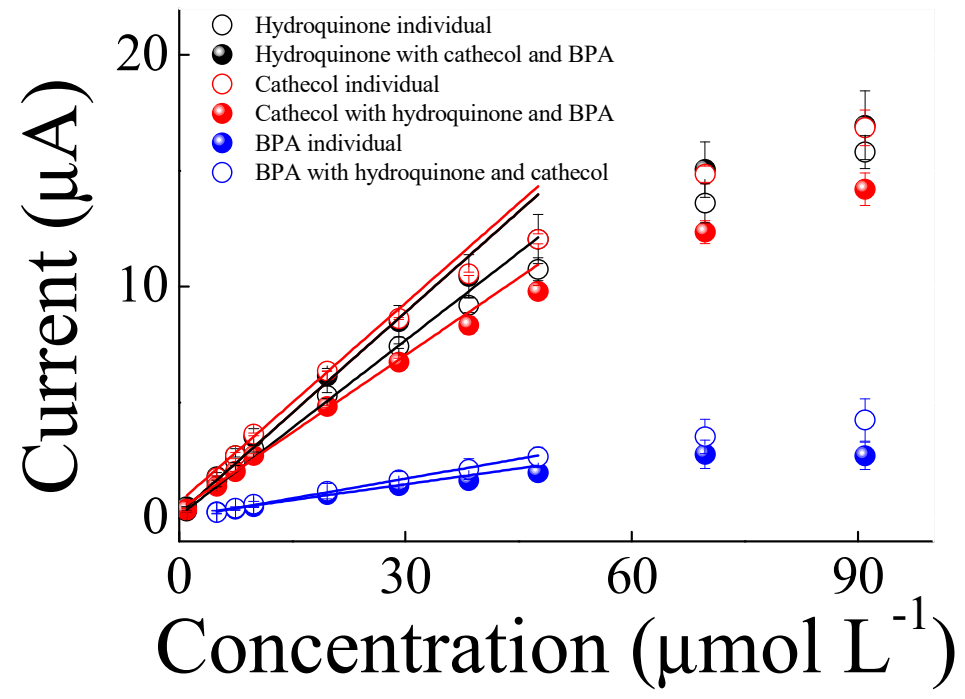

Figure 5. Analytical curves for individual and simultaneous detection of hydroquinone, catechol, and BPA. Conditions: concentration range from 2.0 to $90 \times 10^{-6} \mathrm{~mol} \mathrm{~L}^{-1}$ in phosphate buffer solution $0.1 \mathrm{~mol} \mathrm{~L}^{-1}, \mathrm{pH} 7.0$.

Seven co-fabricated SPEs were utilized for the reproducibility study using $2.0 \times 10^{-5} \mathrm{~mol} \mathrm{~L}^{-1}$ BPA in $0.1 \mathrm{~mol} \mathrm{~L}^{-1}$ phosphate buffer solution ( $\mathrm{pH} 7.0$ ) and DPV technique. The relative standard deviation (RSD) was $5.2 \%$, indicating a satisfactory reproducibility of the fabrication protocol. Flexible SPEs were applied for the simultaneous determination of hydroquinone, catechol, and BPA in water samples using the procedure described in Section 2. The DPV curves in black in Figure 6 show no oxidation peaks for hydroquinone, catechol, and BPA analytes, which means that these analytes were not present in the water samples or that concentrations are below the detection limit. In order to test the SPEs, we spiked the water with phosphate buffer solution and known concentrations of hydroquinone, catechol, and BPA. The recovery values varied from $91.7 \%$ to $104.6 \%$ for the three analytes, as shown in Supplementary Table S2. Therefore, flexible SPEs can be employed in monitoring samples of wastewater, water, and biological fluids, e.g., sweat, saliva, and urine, in real scenarios. The standard addition curves in Figure 7 were obtained from the current peak intensity in DPVs in Figure 6 (measurements were made in triplicate). Linear dependences were observed between $7.5 \times 10^{-6}$ and $3.5 \times 10^{-5} \mathrm{~mol} \mathrm{~L}^{-1}$. The intercepts were zero in Figure $7 \mathrm{~A}, \mathrm{~B}$ in the calibration plots for hydroquinone and catechol, thus indicating that these analytes were not present before the additional experiments. In contrast, the intercept in Figure $7 \mathrm{C}$ for BPA is $(0.53 \pm 0.13) \times 10^{-6} \mathrm{~A}$, corresponding to a BPA concentration of $3.17 \times 10^{-6} \mathrm{~mol} \mathrm{~L}^{-1}$ even before adding any BPA. Hence, there was $0.145 \mathrm{mg}$ BPA in the plastic cups made of polystyrene (PS), representing at least $0.003 \%$ of their mass, which is particularly worrying as BPA contamination could occur with the use of such cups. 


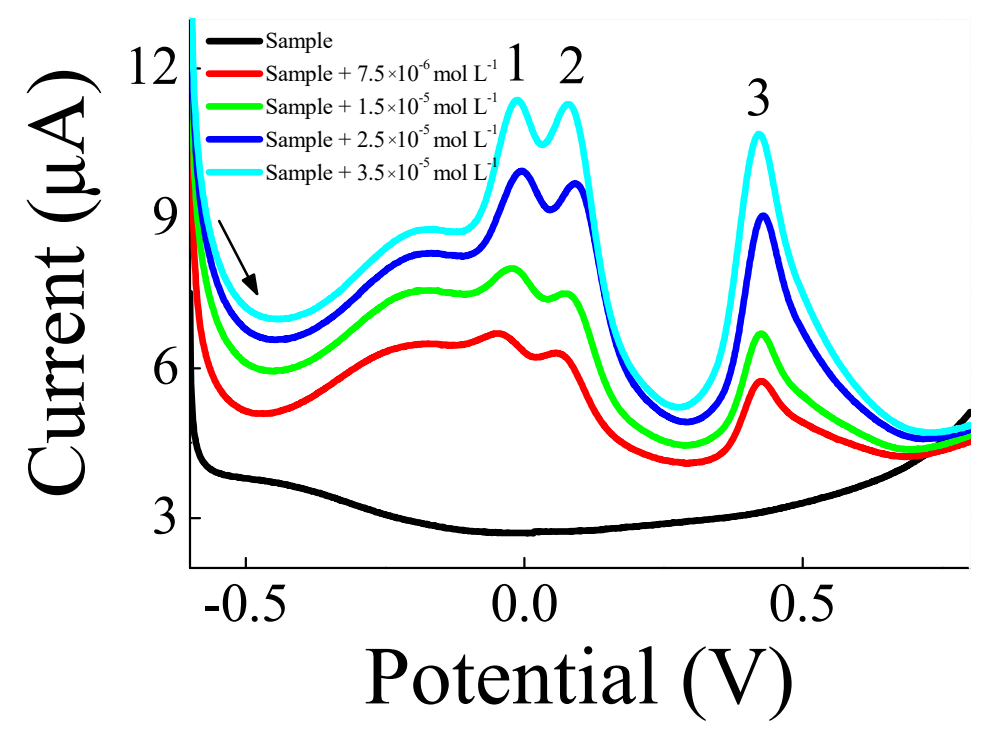

Figure 6. DP Voltammograms for water sample analysis using the method of standard addition. 1-Hydroquinone, 2-Catechol, and 3-BPA. Conditions: phosphate buffer solution $0.1 \mathrm{~mol} \mathrm{~L}^{-1} \mathrm{pH}$ 7.0.

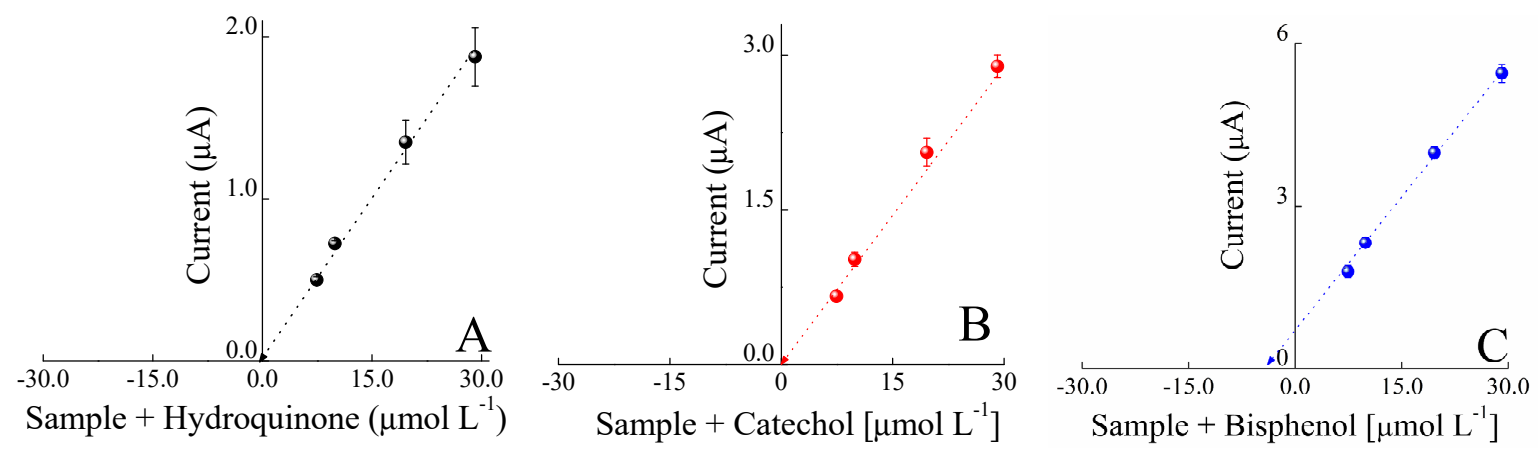

Figure 7. Calibration plots using standard addition to analyze water samples. (A) hydroquinone, (B) catechol and (C) BPA. Conditions: phosphate buffer solution $0.1 \mathrm{~mol} \mathrm{~L}^{-1}, \mathrm{pH} 7.0$.

Supplementary Figure S2 shows the results of selectivity studies for BPA with SPEs on flexible SPEs. DPVs were obtained with $1.0 \times 10^{-5} \mathrm{~mol} \mathrm{~L}^{-1} \mathrm{BPA}$ in the presence of $1.0 \times 10^{-5} \mathrm{~mol} \mathrm{~L}^{-1}$ of co-existing, commonly interfering analytes such as the analgesic paracetamol and the hormone epinephrine. No interference was noted from these co-existing species, with oxidation peaks at $0.20 \mathrm{~V}$ and $0.05 \mathrm{~V}$ vs. C attributed to paracetamol and epinephrine electrooxidation. The BPA anodic peak potential was shifted to a more positive potential due to kinetic limitations at the electrode/solution interface with irreversible adsorption of secondary amine groups from paracetamol and epinephrin on the electrode [32]. The selectivity for BPA is therefore possible because detection occurs at a different oxidation potential. These results also confirm that SPEs can be applied for other compounds in water, such as paracetamol [31] and epinephrine [33,34].

Table 1 lists the analytical performance of carbon-based sensing layers in terms of technique, linear range, sensitivity ( $\mu \mathrm{A} \mathrm{L} \mu \mathrm{mol}^{-1}$ ), and detection limits $\left(\mu \mathrm{mol} \mathrm{L}^{-1}\right)$ for BPA detection. The flexible SPE sensor exhibits sensitivity and detection limit which are competitive with those in the works mentioned. Unlike the SPE sensor, most of them were made with a blend of materials on the carbon surface. Moreover, film architectures require long procedures that consume larger amounts of chemicals and produce waste. Thus, the flexible SPE sensor is advantageous for sensitivity and selectivity, with the potential to be low cost and used in portable systems. 
Table 1. Electrode materials for the detection of BPA.

\begin{tabular}{|c|c|c|c|c|c|}
\hline Sensing Layer & $\begin{array}{c}\text { Type of } \\
\text { Technique }\end{array}$ & $\begin{array}{c}\text { Linear Range } \\
\mu \mathrm{mol} \mathrm{L} \\
-1\end{array}$ & $\begin{array}{l}\text { Sensitivity } \\
\mu \mathrm{A} \mathrm{L} \mu \mathrm{mol}^{-1}\end{array}$ & $\begin{array}{c}\text { LOD } \\
\mu \mathrm{mol} \mathrm{L}-1\end{array}$ & Ref. \\
\hline NiPCTS & DPV & $0.5-10$ & 1.78 & 0.29 & [35] \\
\hline CoPCTS & DPV & $0.5-10$ & 1.57 & 0.43 & [35] \\
\hline MIL/CPE & SWV & $2.0-53$ & 0.42 & 0.87 & {$[36]$} \\
\hline RGO-Ag/PLL/GCE & DPV & $1.0-80$ & 0.15 & 0.54 & [15] \\
\hline CGE/graphene & DPV & $0.05-1$ & 0.010 & 0.05 & [37] \\
\hline EG & SWV & $1.56-50$ & 6.06 & 0.76 & [38] \\
\hline MWCNTs/GCE & DPV & $2-30$ & 0.51 & 0.5 & [39] \\
\hline $\mathrm{SPE}_{\text {individual }}$ & DPV & $2-50$ & $0.046 \pm 0.002$ & 3.41 & This Work \\
\hline $\mathrm{SPE}_{\text {simultaneous }}$ & DPV & $2-50$ & $0.055 \pm 0.001$ & 0.95 & This Work \\
\hline
\end{tabular}

Note: MWCNTs: multi-walled carbon nanotubes; CGE: glassy carbon; SPE: Screen-printed electrodes; EG: Exfoliated graphite; NiPCTS: Pencil graphite electrodes modified with metallophthalocyanine sulfonates of nickel; CoPCTS: Pencil graphite electrodes modified with metallophthalocyanine sulfonates of cobalt; CPE: carbon paste; MIL: Magnetic ionic liquid; SWV: Square wave voltammetry; RGO-Ag/PLL: Reduced graphene oxide-silver/poly-L-lysine nanocomposites.

\section{Conclusions}

We have developed a simple and inexpensive electrochemical sensor for detecting hydroquinone, catechol, and BPA in water samples using disposable flexible screen-printed electrodes. Devices were made on PET flexible substrates using screen-printing technology. Carbon surface features, combined with electroanalytical performance, pointed to increased conductivity and sensitivity, induced by electrode pretreatment in a $0.5 \mathrm{~mol} \mathrm{~L}^{-1} \mathrm{H}_{2} \mathrm{SO}_{4}$ solution. The flexible SPE sensor exhibited detection limit

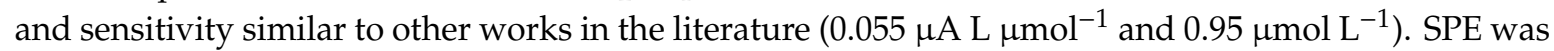
able to distinguish interferences such as paracetamol and epinephrine in real samples. The advantages of this sensing platform are related to selectivity, sensitivity, and simplicity, with the potential to be used in portable systems.

Supplementary Materials: The following are available online at http:/www.mdpi.com/2227-9040/8/4/103/s1, Figure S1: Cyclic Voltammograms for flexible SPEs: (A) Before electrochemical pre-treatment; (B) After electrochemical pretreatment with $0.1 \mathrm{~mol} \mathrm{~L}^{-1}$ of $\mathrm{H}_{2} \mathrm{SO}_{4}$ solution, applying $-2.5 \mathrm{~V}$ vs. C. for $120 \mathrm{~s}$. (C) After electrochemical pretreatment with $0.1 \mathrm{~mol} \mathrm{~L}^{-1}$ of $\mathrm{H}_{2} \mathrm{SO}_{4}$ solution, applying $+2.5 \mathrm{~V}$ vs. C. for $120 \mathrm{~s}$. (D) After electrochemical pretreatment with $0.1 \mathrm{~mol} \mathrm{~L}^{-1}$ of $\mathrm{NaOH}$ solution, applying $+1.2 \mathrm{~V}$ vs. C. for $300 \mathrm{~s}$. The measurements were performed in $0.1 \mathrm{~mol} \mathrm{~L}^{-1}$ of KCL solution ( $\mathrm{pH} \mathrm{7.0)} \mathrm{containing} 5.0 \times 10^{-3} \mathrm{~mol} \mathrm{~L}^{-1}$ of redox probe $[\mathrm{Fe}(\mathrm{CN}) 6]^{4-/ 3-}$ with scan rate $50 \mathrm{mV} \mathrm{s}^{-1}$, Figure S2: DP Voltammograms data on the SPE electrode to verify possible interference of other drugs with $1 \times 10^{-5} \mathrm{~mol} \mathrm{~L}^{-1}$ (1) BPA, (2) Paracetamol, (3) Epinephrine. Conditions: $0.1 \mathrm{~mol} \mathrm{~L}^{-1}$ phosphate buffer solution, $\mathrm{pH}$ 7.0, Table S1: Characteristics of electrochemical pretreatment and change in peak potential for flexible SPEs, Table S2: Results for hydroquinone, catechol and BPA quantification in real samples of plastic cups containing water samples using flexible carbon electrodes.

Author Contributions: A.C.d.S.: Formal analysis, Investigation, Writing-Original Draft, Writing-Review \& Editing and Visualization. S.C.B.: Formal analysis, Investigation, Writing-Original Draft, Writing-Review \& Editing and Visualization. P.A.R.-P.: Conceptualization, Methodology, Resources, Writing-Review \& Editing, Visualization, Supervision and Project administration. D.W.: Resources and Writing-Review \& Editing. F.M.S.: Writing—Review \& Editing. M.R.: Writing—Review \& Editing. O.N.O.J.: Writing—Review \& Editing, Supervision and Funding acquisition. All authors have read and agreed to the published version of the manuscript.

Funding: This research was funded by Fundação de Amparo à Pesquisa do Estado de São Paulo (FAPESP), grant number (Proc. 2018/22214-6 and 2016/01919-6); by Coordenação de Aperfeiçoamento de Pessoal de Nível Superior-Brazil (CAPES), grant number 88887.375050/2019-00 and 88887.375049/2019-00; Conselho Nacional de Desenvolvimento Científico e Tecnológico-CNPq, grant number 153855/2018-5 and 423952/2018-8 and INEO (Brazil).

Acknowledgments: The authors gratefully acknowledge the financial support granted by the Coordenação de Aperfeiçoamento de Pessoal de Nível Superior-Brasil (CAPES)-Finance Code 88887.375050/2019-00 and 88887.375049/2019-00; Fundação de Amparo à Pesquisa do Estado de São Paulo (FAPESP), Proc. (2018/22214-6 and 2016/01919-6); Conselho Nacional de Desenvolvimento Científico e Tecnológico-CNPq (153855/2018-5 and 423952/2018-8) and INEO (Brazil).

Conflicts of Interest: The authors declare no conflict of interest. 


\section{References}

1. Abegao, L.M.G.; Ribeiro, J.H.F.; Ribeiro, P.A.; Raposo, M. Nano-molar deltamethrin sensor based on electrical impedance of PAH/PAZO layer-by-layer sensing films. Sensors 2013, 13, 10167-10176. [CrossRef] [PubMed]

2. Magro, C.; Mateus, E.P.; Paz-Garcia, J.M.; Serio, S.; Raposo, M.; Ribeiro, A.B. Electronic tongue coupled to an electrochemical flow reactor for emerging organic contaminants real time monitoring. Sensors 2019, 19. [CrossRef] [PubMed]

3. Magro, C.; Mateus, E.P.; Raposo, M.; Ribeiro, A.B. Overview of electronic tongue sensing in environmental aqueous matrices: Potential for monitoring emerging organic contaminants. Environ. Rev. 2019, 27, $202-214$. [CrossRef]

4. Marques, I.; Magalhaes-Mota, G.; Pires, F.; Serio, S.; Ribeiro, P.A.; Raposo, M. Detection of traces of triclosan in water. Appl. Surf. Sci. 2017, 421, 142-147. [CrossRef]

5. Motia, S.; Tudor, I.A.; Ribeiro, P.A.; Raposo, M.; Bouchikhi, B.; El Bari, N. Electrochemical sensor based on molecularly imprinted polymer for sensitive triclosan detection in wastewater and mineral water. Sci. Total. Environ. 2019, 664, 647-658. [CrossRef] [PubMed]

6. Campos, A.M.; Raymundo-Pereira, P.A.; Cincotto, F.H.; Canevari, T.C.; Machado, S.A.S. Sensitive determination of the endocrine disruptor bisphenol A at ultrathin film based on nanostructured hybrid material SiO2/GO/AgNP. J. Solid State Electrochem. 2016, 20, 2503-2507. [CrossRef]

7. Chen, X.L.; Wang, C.; Tan, X.M.; Wang, J.X. Determination of bisphenol A in water via inhibition of silver nanoparticles-enhanced chemiluminescence. Anal. Chim. Acta 2011, 689, 92-96. [CrossRef]

8. Konieczna, A.; Rutkowska, A.; Rachon, D. Health risk of exposure to Bisphenol A (BPA). Rocz. Panstw. Zakl. Hig. 2015, 66, 5-11.

9. Reddy, P.V.L.; Kim, K.H.; Kavitha, B.; Kumar, V.; Raza, N.; Kalagara, S. Photocatalytic degradation of bisphenol A in aqueous media: A review. J. Environ. Manag. 2018, 213, 189-205. [CrossRef]

10. Manimegala, S.; Sendhilvadivu, D.M. Antidiabetic Effect of Ginger (Zingiber officinali) and Oregano (Oregano vulgare) in BPA Induced Catfishes. Int. J. Sci. Res. 2019, 8, 1364-1367.

11. Vandentorren, S.; Zeman, F.; Morin, L.; Sarter, H.; Bidondo, M.L.; Oleko, A.; Leridon, H. Bisphenol-A and phthalates contamination of urine samples by catheters in the Elfe pilot study: Implications for large-scale biomonitoring studies. Environ. Res. 2011, 111, 761-764. [CrossRef]

12. Hu, J.Y.; Cheng, S.J.; Aizawa, T.; Terao, Y.; Kunikane, S. Products of aqueous chlorination of 17 beta-estradiol and their estrogenic activities. Environ. Sci. Technol. 2003, 37, 5665-5670. [CrossRef]

13. Karabiberoglu, S.U. Sensitive voltammetric determination of bisphenol a based on a glassy carbon electrode modified with copper oxide-zinc oxide decorated on graphene oxide. Electroanalysis 2019, 31, 91-102. [CrossRef]

14. Olea, N.; Arrebola, J.P.; Taoufiki, J.; Fernandez-Valades, R.; Prada, R.; Navea, N.; Molina-Molina, J.M.; Fernandez, M.F. Alkylphenols and bisphenol-A and its chlorinated derivatives in adipose tissue of children. Wit. Trans. Ecol. Environ. 2008, 110, 129-138. [CrossRef]

15. Li, Y.H.; Wang, H.Q.; Yan, B.; Zhang, H.Y. An electrochemical sensor for the determination of bisphenol A using glassy carbon electrode modified with reduced graphene oxide-silver/poly-L-lysine nanocomposites. J. Electroanal. Chem. 2017, 805, 39-46. [CrossRef]

16. Ragavan, K.V.; Rastogi, N.K.; Thakur, M.S. Sensors and biosensors for analysis of bisphenol-A. TrAC Trends Anal. Chem. 2013, 52, 248-260. [CrossRef]

17. Zhu, C.Z.; Yang, G.H.; Li, H.; Du, D.; Lin, Y.H. Electrochemical sensors and biosensors based on nanomaterials and nanostructures. Anal. Chem. 2015, 87, 230-249. [CrossRef]

18. Baccarin, M.; Ciciliati, M.A.; Oliveira, O.N.; Cavalheiro, E.T.G.; Raymundo-Pereira, P.A. Pen sensor made with silver nanoparticles decorating graphite-polyurethane electrodes to detect bisphenol-A in tap and river water samples. Mater. Sci. Eng. C 2020, 114, 110989. [CrossRef]

19. Raymundo-Pereira, P.A.; Campos, A.M.; Prado, T.M.; Furini, L.N.; Boas, N.V.; Calegaro, M.L.; Machado, S.A.S. Synergy between printex nano-carbons and silver nanoparticles for sensitive estimation of antioxidant activity. Anal. Chim. Acta 2016, 926, 88-98. [CrossRef]

20. Raymundo-Pereira, P.A.; Gomes, N.O.; Carvalho, J.H.S.; Machado, S.A.S.; Oliveira, O.N., Jr.; Janegitz, B.C. Simultaneous detection of quercetin and carbendazim in wine samples using disposable electrochemical sensors. ChemElectroChem 2020, 7, 3074-3081. [CrossRef] 
21. Carr, O.; Raymundo-Pereira, P.A.; Shimizu, F.M.; Sorroche, B.P.; Melendez, M.E.; Pedro, R.D.; Miranda, P.B.; Carvalho, A.L.; Reis, R.M.; Arantes, L.M.R.B.; et al. Genosensor made with a self-assembled monolayer matrix to detect MGMT gene methylation in head and neck cancer cell lines. Talanta 2020, 210. [CrossRef] [PubMed]

22. Pupin, R.R.; Foguel, M.V.; Goncalves, L.M.; Sotomayor, M.D.T. Magnetic molecularly imprinted polymers obtained by photopolymerization for selective recognition of penicillin G. J. Appl. Polym. Sci. 2020, 137. [CrossRef]

23. Quinto, M.L.; Khan, S.; Picasso, G.; Sotomayor, M.D.T. Synthesis, characterization, and evaluation of a selective molecularly imprinted polymer for quantification of the textile dye acid violet 19 in real water samples. J. Hazard. Mater. 2020, 384, 121374. [CrossRef]

24. Niu, X.L.; Yang, W.; Wang, G.Y.; Ren, J.; Guo, H.; Gao, J.Z. A novel electrochemical sensor of bisphenol A based on stacked graphene nanofibers/gold nanoparticles composite modified glassy carbon electrode. Electrochim. Acta 2013, 98, 167-175. [CrossRef]

25. Bishop, G.W.; Ahiadu, B.K.; Smith, J.L.; Patterson, J.D. Use of redox probes for characterization of layer-by-layer gold nanoparticle-modified screen-printed carbon electrodes. J. Electrochem. Soc. 2017, 164, B23-B28. [CrossRef]

26. Silva, R.R.; Raymundo-Pereira, P.A.; Campos, A.M.; Wilson, D.; Otoni, C.G.; Barud, H.S.; Costa, C.A.R.; Domeneguetti, R.R.; Balogh, D.T.; Ribeiro, S.J.L.; et al. Microbial nanocellulose adherent to human skin used in electrochemical sensors to detect metal ions and biomarkers in sweat. Talanta 2020, 218, 121153. [CrossRef]

27. Mocak, J.; Bond, A.M.; Mitchell, S.; Scollary, G. A statistical overview of standard (IUPAC and ACS) and new procedures for determining the limits of detection and quantification: Application to voltammetric and stripping techniques (technical report). Pure Appl. Chem. 1997, 69, 297-328. [CrossRef]

28. Canevari, T.C.; Raymundo-Pereira, P.A.; Landers, R.; Machado, S.A.S. Direct synthesis of ag nanoparticles incorporated on a mesoporous hybrid material as a sensitive sensor for the simultaneous determination of dihydroxybenzenes isomers. Eur. J. Inorg. Chem. 2013, 2013, 5746-5754. [CrossRef]

29. Raymundo-Pereira, P.A.; Campos, A.M.; Mendonca, C.D.; Calegaro, M.L.; Machado, S.A.S.; Oliveira, O.N. Printex 6L carbon nanoballs used in electrochemical sensors for simultaneous detection of emerging pollutants hydroquinone and paracetamol. Sensor Actuat. B Chem. 2017, 252, 165-174. [CrossRef]

30. González-Sánchez, M.I.; Gómez-Monedero, B.; Agrisuelas, J.; Iniesta, J.; Valero, E. Electrochemical performance of activated screen printed carbon electrodes for hydrogen peroxide and phenol derivatives sensing. J. Electroanal. Chem. 2019, 839, 75-82. [CrossRef]

31. Raymundo-Pereira, P.A.; Gomes, N.O.; Machado, S.A.S.; Oliveira, O.N. Simultaneous, ultrasensitive detection of hydroquinone, paracetamol and estradiol for quality control of tap water with a simple electrochemical method. J. Electroanal. Chem. 2019, 848. [CrossRef]

32. Canevari, T.C.; Raymundo-Pereira, P.A.; Landers, R.; Benvenutti, E.V.; Machado, S.A. Sol-gel thin-film based mesoporous silica and carbon nanotubes for the determination of dopamine, uric acid and paracetamol in urine. Talanta 2013, 116, 726-735. [CrossRef] [PubMed]

33. Beduk, T.; Lahcen, A.A.; Tashkandi, N.; Salama, K.N. One-step electrosynthesized molecularly imprinted polymer on laser scribed graphene bisphenol a sensor. Sensor Actuat. B Chem. 2020, 314. [CrossRef]

34. Zhan, T.R.; Song, Y.; Li, X.J.; Hou, W.G. Electrochemical sensor for bisphenol A based on ionic liquid functionalized Zn-Al layered double hydroxide modified electrode. Mat. Sci. Eng. C Mater. 2016, 64, 354-361. [CrossRef] [PubMed]

35. Ozcan, L.; Altuntas, M.; Buyuksagis, A.; Turk, H.; Yurdakal, S. Electrochemical determination of bisphenol A with pencil graphite electrodes modified with $\mathrm{Co}(\mathrm{II}), \mathrm{Ni}(\mathrm{II}), \mathrm{Cu}(\mathrm{II})$ and $\mathrm{Fe}(\mathrm{II})$ phthalocyaninetetrasulfonates. Anal. Sci. 2016, 32, 881-886.

36. Silva, T.R.; Merib, J.; Spudeit, D.A.; Carasek, E.; Vieira, I.C. Electrode modified with the ionic liquid [P-6,6,6,14(+)](2)[MnCl42-] for the determination of bisphenol A in plastic samples. J. Brazil. Chem. Soc. 2019, 30, 2076-2084. [CrossRef]

37. Ntsendwana, B.; Mamba, B.B.; Sampath, S.; Arotiba, O.A. Electrochemical detection of bisphenol A using graphene-modified glassy carbon electrode. Int. J. Electrochem. Sci. 2012, 7, 3501-3512. 
38. Ndlovu, T.; Arotiba, O.A.; Sampath, S.; Krause, R.W.; Mamba, B.B. An exfoliated graphite-based Bisphenol A electrochemical sensor. Sensors 2012, 12, 11601-11611. [CrossRef]

39. Wang, X.; Li, M.J.; Wu, M.; Shi, Y.R.; Yang, J.J.; Shan, J.J.; Liu, L.F. Simultaneous determination of Bisphenol A and Bisphenol S using multi-walled carbon nanotubes modified electrode. Int. J. Electrochem. Sci. 2018, 13, 11906-11922. [CrossRef]

Publisher's Note: MDPI stays neutral with regard to jurisdictional claims in published maps and institutional affiliations.

(C) 2020 by the authors. Licensee MDPI, Basel, Switzerland. This article is an open access article distributed under the terms and conditions of the Creative Commons Attribution (CC BY) license (http://creativecommons.org/licenses/by/4.0/). 